\title{
Community v. non-community assault among adults in Khayelitsha, Western Cape, South Africa: A case count and comparison of injury severity
}

\author{
S Forgus, ${ }^{1} \mathrm{MB}$ ChB; W Delva, ${ }^{2-4} \mathrm{MD}$, PhD; C Hauptfleisch, ${ }^{1}$ S Govender, ${ }^{1} \mathrm{MB}$ ChB, MFamMed; J Blitz, ${ }^{1} \mathrm{MB} \mathrm{ChB}, \mathrm{MFamMed}$ \\ ${ }^{1}$ Division of Family Medicine and Primary Care, Faculty of Medicine and Health Sciences, Stellenbosch University, Tygerberg, South Africa \\ ${ }^{2}$ DST/NRF Centre of Excellence in Epidemiological Modelling and Analysis (SACEMA), Stellenbosch University, South Africa \\ ${ }^{3}$ International Centre for Reproductive Health, Ghent University, Ghent, Belgium \\ ${ }^{4}$ Center for Statistics, Hasselt University, Diepenbeek, Belgium
}

Corresponding author: S Forgus (sforgus@gmail.com)

\begin{abstract}
Background. Community assault (CA) or vigilantism is widespread in the township of Khayelitsha, Cape Town, South Africa (SA). Anecdotal evidence suggests that victims of CA are worse off than other assault cases. However, scientific data on the rate and severity of CA cases are lacking for SA.

Objectives. To contribute to CA prevention and management strategies by estimating the rate of CA among adults in Khayelitsha and comparing the injury severity and survival probability between cases of CA and other assault (non-CA) cases.

Methods. We studied four healthcare centres in Khayelitsha during July - December 2012. A consecutive case series was conducted to capture all CA cases during this period. A retrospective folder review was performed on all cases of CA and on a control group of non-CA cases to compare injury severity and estimate survival probability.

Results. A total of 148 adult cases of CA occurred (case rate 1.1/1 000 person-years) over the study period. The Injury Severity Scores (ISSs) in the CA group were significantly higher than in the non-CA group $(p<0.001)$, with a median (interquartile range) ISS of 3 (2 - 6$)$ in CA cases v. 1 ( 1 - 2) in non-CA cases. Comparison between the CA v. non-CA groups showed that a Glasgow Coma Scale $<15$ (20.1\% v. $5.4 \%$, respectively), referral to the tertiary hospital (33.8\% v. $22.6 \%$, respectively), and crush syndrome ( $25.7 \%$ v. $0.0 \%$, respectively) were all more common in CA cases. Survival probabilities were similar in both groups (CA v. non-CA 99.2\% v. 99.3\%, respectively).

Conclusion. The rate of CA among adults in Khayelitsha is high, and the severity of injuries sustained by CA victims is substantially higher than in other assault cases.
\end{abstract}

S Afr Med J 2014;104(4):299-301. DOI:10.7196/SAMJ.7615

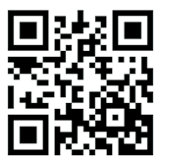

Rapid and uncontrolled urbanisation in the black population of South Africa (SA) in the mid-1990s was associated with deteriorating conditions in urban and peri-urban slums and increasing levels of violence. ${ }^{[1]}$ Although crime rates have been decreasing steadily since then, SA still has among the highest burdens of interpersonal violence injury in the world. ${ }^{[2]}$ Since many of the poorer, black, rural or urban informal settlements in SA are poorly designed without proper roads, streetlights or maintained pathways, state police are often loathe to or afraid to patrol such areas. ${ }^{[3]}$ The legacy of apartheid has also left a deep mistrust of the police, as public-order policing under this regime was often associated with the use of force ${ }^{[4]}$ As a result, communities have sought out alternative means of establishing law and order and implementing justice by taking the law into their own hands and meting out punishment using violence. This phenomenon, referred to globally as vigilantism, is not unique to developing countries. ${ }^{[5]}$ In SA, the terms community assault (CA), community justice, people's courts and kangaroo courts are used. ${ }^{[6]}$ These appear to have their origins in traditional African principles of restorative justice (lekgotla) ${ }^{[7]}$ In this paper, the term CA will be used, as this is the name most often used in emergency units in SA.

Media reports seem to imply that this form of community-initiated policing is rife in the townships of SA ${ }^{[8]} \mathrm{CA}$ has often been observed to involve the use of sjamboks - robust whips traditionally made from hippopotamus or rhinoceros hide. ${ }^{\left[{ }^{[]}\right.}$The blunt forces produced by sjamboks inflict extensive soft-tissue trauma and crush syndrome. ${ }^{[10]}$ Anecdotal evidence suggests that victims of CA are more severely injured than their non-CA counterparts.

Owing to the lack of any formal evaluation of the frequency and severity of CAs, the burden of this phenomenon on the SA healthcare system is unknown. To this end, we conducted a consecutive case series of CA and non-CA cases at four state healthcare facilities in Khayelitsha, a partially informal township in Cape Town, Western Cape, to estimate the rate of cases and their severity.

\section{Methods}

\section{Study sites and study population}

Study sites comprised all state healthcare facilities in Khayelitsha with emergency care (three provincial government clinics and one district hospital). The study population consisted of adult victims of CA and a comparator group. The victims of CA were either self-identified or identified as such by their escorts (family members, police officers or ambulance personnel). The comparator group were victims of non-CAs, defined as any other victim of assault where the patients neither identified themselves nor were identified by any other person as being victims of CA. 
This study received ethical approval from the Stellenbosch University Health Research Ethics Committee (ref. N11/07/212).

\section{Data collection}

Emergency unit registries were used to identify cases and data were collected retrospectively by folder review for both study groups. Based on informed guesses of the incidence of $\mathrm{CA}$ and non-CA, it was decided that data for the CA group would be collected over a period of 6 months from 1 July to 31 December 2012, while data for the non-CA group would be collected over a period of 8 days from 1 to 8 July 2012 .

\section{Variables}

A number of binary indicators were used to assess injury severity, including: a Glasgow Coma Scale (GCS) $<15$, presence of crush syndrome, whether or not patients required intubation, and the necessity for referral to a higher level of care. Crush syndrome was defined as rhabdomyolysis (evidence of skeletal muscle injury) with a documented elevated creatine kinase level $>3$ times the upper limit of normal $(>1000 \mathrm{U} / \mathrm{l})^{\left[{ }^{[11]}\right.}$ Referral occurred either from the clinics to the district hospital for admission or imaging (X-rays after hours) or from district to tertiary level for advanced imaging, specialist opinion, surgery or intensive care if intubated and ventilated.

Each case was also given an Injury Severity Score (ISS). The ISS, though not commonly used in SA, is widely used internationally and has become an integral part of all trauma registry-based severity assessment tools. The ISS is based on an anatomical scoring system (the Abbreviated Injury Score (AIS) 2005), which codes the body into nine different body regions and assigns each injury 1/6 severity scores (AIS scores). ${ }^{[12]}$ The ISS (ranging from 1 to 75 ) is then calculated by taking the sum of the squares of the highest AIS scores in each of the three most severely affected body regions. Lastly, the probability of survival was calculated using the Trauma Audit and Research Network Outcome Prediction Model based on the ISS, age, gender and GCS of the patient and whether or not the patient was intubated. ${ }^{[13]}$

\section{Data management and statistical analysis}

Data were entered into EpiInfo 7 by a research assistant and systematically checked by the principal investigator. To estimate the rate of CA and non-CA, the number of cases was divided by the product of the estimated adult population in Khayelitsha aged $\geq 18$ years ${ }^{[14]}$ and the period over which the cases were observed. To compare the severity of injuries, the frequencies and percentages of the binary severity indicators were tabulated and visualised, and relative risk (RR) with surrounding $95 \%$ confidence intervals (CIs) and associated $p$-values were computed. Further, the median and interquartile range (IQR) of the ISS and the average survival probability were calculated for both groups. Formal comparison of the distribution of the ISS was done using a Mann-Whitney $U$ test, while the average survival probabilities were compared using a Student's $t$-test. All statistical analyses were performed using $\mathrm{R}^{[15]}$

\section{Results}

In the first 8 days of July 2012, 115 cases of non-CA were recorded, and over the entire second half of 2012, data from a total of 148 CA cases were extracted. The age of CA cases ranged from 18 to 61 years (median 24; IQR 21 - 30). In the non-CA group, ages ranged from 18 to 57 years (median 25.5; IQR 22 - 33.5). A minority of all assault cases were female: $27 / 115(23.5 \%)$ in the non-CA

Table 1. Comparison of binary injury severity indicators in CA and non-CA cases

\begin{tabular}{llllll}
\hline \multicolumn{5}{c}{} & \multicolumn{4}{c}{ Assault, $\%$} & & \\
\cline { 2 - 3 } & $\mathbf{C A}(\mathbf{N = 1 4 8})$ & Non-CA $(\mathbf{N = 1 1 5})$ & RR & 95\% CI & p-value \\
\hline GCS $<15$ & 20.1 & 5.4 & 3.73 & $1.60-8.66$ & $<0.001$ \\
Crush syndrome & 25.7 & 0.0 & NA & NA & NA \\
Referral & 33.7 & 22.6 & 1.49 & $1.00-2.24$ & 0.055 \\
Intubation & 4.7 & 3.5 & 1.36 & $0.41-4.53$ & 0.76 \\
CA = community assault; GCS = Glasgow Coma Scale; $\mathrm{RR}=$ relative risk; $\mathrm{CI}=$ confidence interval; $\mathrm{NA}=$ not applicable.
\end{tabular}

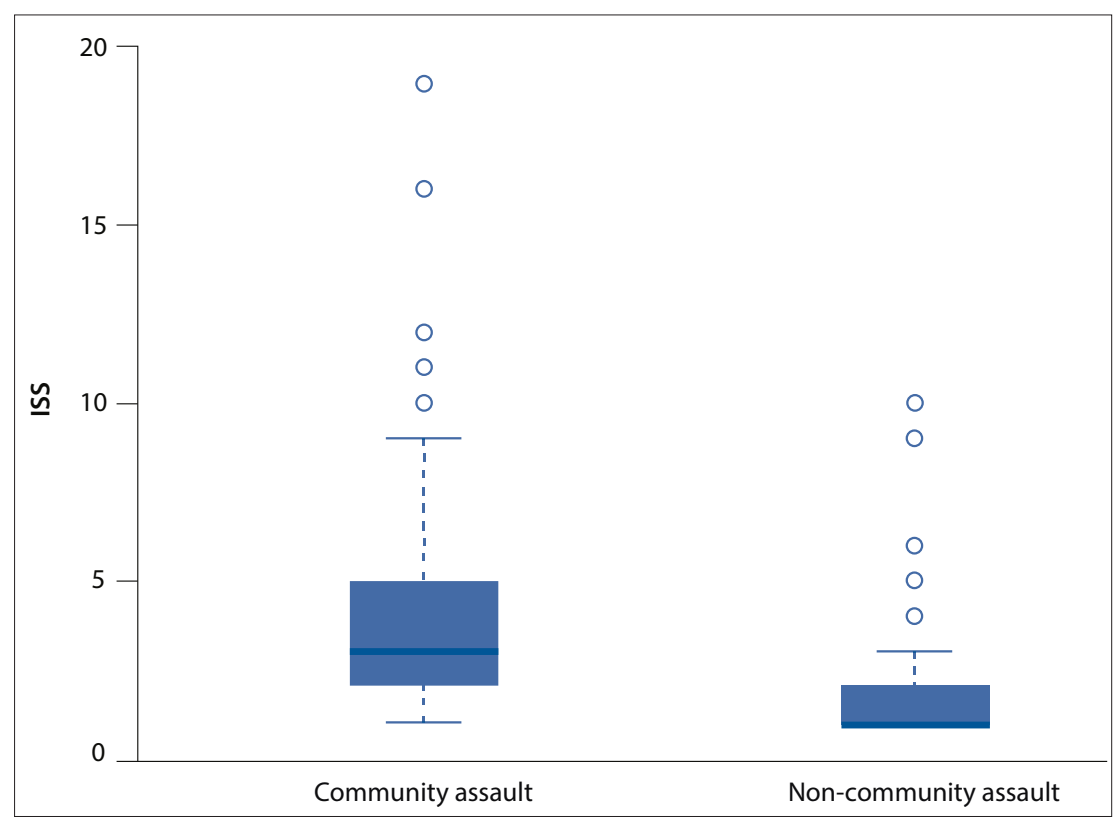

Fig. 1. Injury Severity Scores (ISSs) in community and non-community assault cases. group and $2 / 148(1.4 \%)$ in the CA group $(p<0.001$, Fisher's exact test).

\section{Rate of assault cases}

Based on an estimate population of 275300 adults in Khayelitsha of $\geq 18$ years, the rate of adult cases of CA that received healthcare in Khayelitsha was 1.1/1 000 person-years. For non-CA, the estimated rate was $19 / 1000$ person-years.

\section{Injury severity indicators}

All binary injury severity indicators were with their non-CA counterparts (Table 1).

The majority of cases in both groups had a GCS of 15 . However, in the CA group, $20.1 \%$ $(29 / 144)$ had a GCS $<15$, while this was true for only $5.4 \%(6 / 111)$ of the non-CA group (RR 3.73; 95\% CI 1.60 - 8.66; $p<0.001$ ). In the CA group, $25.7 \%$ (38/148) had crush syndrome while in the non-CA group, nobody had crush syndrome. One-third of cases (50/148) in the CA group were referred for further investigations and management, while $22.6 \%$ of cases $(26 / 115)$ in the non-CA more prevalent among CA cases compared 
group were referred (RR $1.49 ; 95 \%$ CI $1.00-2.24 ; p=0.055$ ). In the CA group, $4.7 \%$ (7/148) of cases were intubated v. 3.5\% (4/115) in the non-CA group (RR 1.36; 95\% CI $0.41-4.53 ; p=0.76$ ).

\section{ISS and survival probability}

The ISS ranged from 1 to 19 in the CA group and from 1 to 10 in the non-CA group with a median (IQR) ISS of $3(2-5)$ v. $1(1-2)$, respectively (Fig. 1). This difference in the ISS distribution between the groups was highly significant ( $p<0.001$, Mann-Whitney $U$ test). The average survival probabilities were very similar in both groups (99.2\% in the CA group v. $99.3 \%$ in non-CA group; $p=0.66$, Student's $t$-test).

\section{Discussion}

A significantly higher proportion of CA patients had a GCS $<15$, developed crush syndrome and were referred (borderline significant), while there was no significant difference between the CA and non-CA groups in the proportion of patients that were intubated. Significantly higher ISSs were observed in the CA group than in the non-CA group, but survival probabilities were similar between the two groups.

This study had a few limitations. Most importantly, the severity of at least some of the referred cases was underestimated. The AIS coding rules and guidelines require that injuries be substantiated by some form of diagnostic or radiographic procedure, surgery or autopsy in order to be assigned an AIS code ${ }^{[12]}$ This resulted in conservative coding of the injuries of patients referred to another facility for these procedures, as the researchers did not have access to clinical data after referral. As a result, a lower ISS was calculated for these cases, which in turn also influenced the survival probability estimates. Furthermore, nine cases in the CA group had sustained head injuries severe enough to render them unconscious or result in a GCS sufficiently low enough that they were unable to identify themselves or provide a date of birth. Consequently, these cases were excluded from the study, based on the inability to classify these patients as being over the age of 18 years. Victims of CA often hide for hours after the assault and lack the community support necessary to seek medical attention. ${ }^{[9]}$ As a result, this study did not include those cases of CA who died prior to seeking medical attention and those who did not seek medical attention at all.

Despite these limitations, we believe that our study is an important contribution to the research on violence-induced injuries in SA. To our knowledge, our study is the first ever to provide objective estimates of the incidence and severity of CA cases. While the Cape Town Trauma Registry Pilot study and the National Injury Mortality Surveillance System offer insight into the magnitude and characteristics of violence with regard to homicide, violence against women and children, traffic-related and other unintentional injuries, ${ }^{[16]}$ they do not allow for the sub-categorisation of CAs as a form of interpersonal violence in SA.

Vigilantism is a complex phenomenon for which there is no quickfix solution. Emergency medical care only addresses the symptoms of this social disease, and not the root causes. This does not mean, however, that healthcare providers do not have a crucial, pro-active role to play in the development and implementation of strategies to improve prevention and management of CA. We argue that CA is first and foremost a primary and district level healthcare issue, for two reasons. Firstly, just as for other victims of trauma in informal settlements, victims of CA present to their local clinic or district hospital. Secondly, the community-orientated approach of primary care embraces community-based strategies for problem solving. Intersectoral collaborations between family physicians, community elders, community forums, the police and policymakers are required to develop and implement various solutions. Strategies include promoting community cohesion and equity, and improving community-police relations. ${ }^{[4]}$ The former strategy can reduce the threshold for everyday violent behaviour. ${ }^{[2]}$ Healthy community-police relations are essential to reach a balance where the law is protected, while simultaneously allowing the community to organise and protect themselves. This will mean disbanding those vigilante groups who violate human rights while allowing the police to supervise activities that operate within the law. ${ }^{[4]}$ This allows a niche for lekgotla to coexist with the current criminal justice system. ${ }^{[1]}$

Further research is required to assess the problem of CAs at other facilities and over longer periods of time. This will provide local data to inform resource distribution within the district healthcare system and to focus prevention efforts on CA hotspots. Social science research may help to improve our understanding of the psychology and sociology behind CAs and to develop evidence-led prevention strategies, the feasibility and effectiveness of which would also require study.

\section{Conclusion}

Through systematic, multi-site recording of CA cases, we obtained objective measures of the rate and injury severity of CA cases in a large peri-urban area near Cape Town. Our findings beg for multisectoral action to curb the medical and social consequences of violent crime in SA.

Acknowledgements. We thank the clerical staff at Khayelitsha District Hospital (KDH), Site B and Nolungile and Michael Mapongwana clinics in Khayelitsha. In particular, we thank Cwengisa Magayana for her assistance in obtaining access to the folders and electronic folder system at $\mathrm{KDH}$. We are indebted to the Rural Medical Education Partnership Initiative, Stellenbosch University, for their support from the US President's Emergency Plan for AIDS Relief through the Health Resources and Services Administration under the terms of T84HA21652.

\section{References}

1. Gilbert L Urban violence and health - South Africa 1995. Soc Sci Med 1996:43(5):873-886. [http// dx.doi.org/10.1016/0277-9536(96)00131-1]

2. Norman R, Matzopoulos R, Groenewald P, Bradshaw D. The high burden of injuries in South Africa. 2. Norman R, Matzopoulos R, Groenewald P, Bradshaw D. The high burden of injuries in S
Bull World Health Organ 2007;85(9):695-702. [http://dx.doi.org/10.2471/BLT.06.037184] Singh D. Resorting to community justice when state policing fails: South Africa. Acta Criminologica Singh D. Resorting

2005; $18(3): 43-50$

Ward C, Artz L, Berg J, et al. Violence, violence prevention, and safety: A research agenda for South Africa. S Afr Med J 2012;102(4):215-218.

5. Huggins M. Vigilantism and the State in Modern Latin America: Essays on Extralegal Violence. New York: Praeger, 1991.

Masiloane DT. Proactive policing for the rich and reactive policing for the poor: Hypocrisy in policing in a stratified society. S Afr J Crim Just 2007;20(3):328-340.

Monaghan R. Community-based justice in Northern Ireland and South Africa. International Criminal Justice Review 2008;18(1):83-105. [http://dx.doi.org/10.1177/1057567708316639]

8. Brinley Bruton F. 'Out of control': Vigilante justice grips impoverished South African slum. NBC News, Brinley Bruton F. 'Out of control': Vigilante justice grips impoverished South African slum. NBC News,
30 June 2013. http://worldnews.nbcnews.com/_news/2013/06/30/19073793-out-of-control-vigilante30 June 2013. http://worldnews.nbcnews.com/_news/2013/06/30/19073793-out-of-co

justice-grips-impoverished-south-african-slum?lite (accessed 2 September 2013).
9. Proctor M, Carter N, Barker P. Community assault - the cost of rough justice. S Afr Med J Proctor M, Carter

10. Erek E, Sever M, Serdengeçti K, et al. An overview of morbidity and mortality in patients with acute renal failure due to crush syndrome: The Marmara earthquake experience. Nephrol Dial Transplan 2002;17(1):33-40. [http://dx.doi.org/10.1093/ndt/17.1.33]

11. Rosedale K, Wood D. Traumatic rhabdomyolysis (crush syndrome) in the rural setting. S Afr Med 2012;102(1):37-39.

12. Gennarelli TA, Wodzin E. AIS 2005: A contemporary injury scale. Injury 2006;37(12):1083-1091 [http://dx.doi.org/10.1016/j.injury.2006.07.009]

13. De Jongh $M$, Verhofstad $M$, Leenen L. Accuracy of different survival prediction models in a trauma population. Br J Surg 2010;97(12):1805-1813. [http://dx.doi.org/10.1002/bjs.7216]

14. Statistics South Africa. Census 2011. Pretoria: Stats SA, 2012. https://www.statssa.gov.za/census2011/ default.asp (accessed 2 September 2013).

5. R Development Core Team. R: A language and environment for statistical computing. Vienna: $\mathrm{R}$ Foundation for Statistical Computing, 2011. http://www.R-project.org/ (accessed 2 September 2013).

16. Schuurman N, Cinnamon J, Matzopoulos R, Fawcett V, Nicol A, Hameed M. Collecting injury surveillance data in low- and middle-income countries: The Cape Town Trauma Registry pilot. Global Public Health 2011;6(8):874-889. [http://dx.doi.org/10.1080/17441692.2010.516268]

Accepted 12 November 2013 